\title{
GAMBARAN EVALUASI PENILAIAN MAHASISWA PROGRAM STUDI PENDIDIKAN DOKTER TERHADAP LINGKUNGAN PEMBELAJARANNYA
}

\author{
Agustina Arundina Triharja Tejoyuwono*, Ita Armyanti**, Rangga Putra Nugraha*** \\ * Departemen Ilmu Kesehatan Masyarakat, Prodi Pendidikan Dokter, Fakultas Kedokteran Universitas Tanjungpura \\ ** Departemen Farmakologi, Prodi Pendidikan Dokter, Fakultas Kedokteran Universitas Tanjungpura \\ *** Departemen Mikrobiologi, Prodi Pendidikan Dokter, Fakultas Kedokteran Universitas Tanjungpura
}

\section{ABSTRACT}

Background: Medical science program Faculty of Medicine Tanjungpura University implements a Competency-Based Curriculum or in Indonesian called as Kurikulum Berbasis Kompetensi (KBK), corresponded to the Kurikulum Inti Pendidikan Tinggi III (KIPDI III). The curriculum is applied since academic year of 2005/2006 and has been evaluated into Curriculum of 2013 (Kurikulum 2013). Learning environment is the manifestation of a curriculum, so that the assessment of the environment in the institution of medical program is a part of the implementation of the evaluation of the curriculum. DREEM questionnaire (Dundee Ready Education Environment Measure) is one of the tools that are appropriate to measure the learning environment. This research aims to assess the students' perception of the learning environment on academic year of 2013/2014.

Method: This research is a descriptive study with cross sectional design, conducted to measure the learning environment in students of medical science program. The DREEM questionnaire was used as the measurement tool. This research was conducted in November 2013 at Faculty of Medicine Tanjungpura University, Pontianak, West Borneo.

Results: The total score of the DREEM obtained in this research is 14,55/200, which shows that students considered the learning environment, including lecturers, social environment, learning process, academic achievement, and learning atmosphere as positive environment. The students assumed that the environment could still be improved by optimizing the resources.

Conclusion: The students inferred that the learning environment could still be improved by optimizing the existing resources as well as getting support by the faculty and university administrators itself.

Keywords: curriculum, medical science program, learning environment, DREEM

\section{ABSTRAK}

Latar belakang: Prodi Pendidikan Dokter Fakultas Kedokteran Universitas Tanjungpura menerapkan Kurikulum Berbasis Kompetensi (KBK) sesuai dengan Kurikulum Inti Pendidikan Tinggi III (KIPDI III). Kurikulum ini diterapkan sejak tahun ajaran 2005/2006, dan telah dievaluasi menjadi Kurikulum 2013, sejak tahun ajaran 2013/2014. Lingkungan pembelajaran merupakan manifestasi dari sebuah kurikulum, sehingga penilaian dari lingkungan tersebut dalam sebuah institusi pendidikan kedokteran, merupakan bagian dari pelaksanaan evaluasi kurikulum. Kuesioner DREEM (Dundee Ready Education Environment Measure) merupakan salah satu alat yang tepat untuk dalam melakukan pengukuran lingkungan pembelajaran. Penelitian ini bertujuan untuk menilai persepsi mahasiswa PSPD FK UNTAN terhadap lingkungan pembelajaran pada tahun akademik 2013/2014.

Metode: Penelitian ini merupakan penelitian deskriptif cross section, yang dilakukan untuk mengukur lingkungan pembelajaran pada mahasiswa PDPD FK UNTAN. Pengukuran dilakukan melalui kuesioner

korespondensi: ita.armyanti@gmail.com 
DREEM (dalam bahasa Inggris). Penelitian ini dilakukan pada bulan November 2013 di FK UNTAN, Pontianak, Kalimantan Barat.

Hasil: Nilai total DREEM yang diperoleh pada penelitian ini adalah 142,55/200 yang menunjukkan bahwa mahasiswa menganggap lingkungan pembelajaran yang ada saat ini, termasuk dosen, lingkungan sosial, proses pembelajaran, capaian akademik, dan suasana pembelajaran, berada dalam lingkungan yang positif. Mahasiswa menganggap bahwa lingkungan tersebut masih dapat ditingkatkan, dengan mengoptimalkan sumber daya yang ada.

Kesimpulan: Mahasiswa berpendapat bahwa lingkungan pembelajaran tersebut dapat ditingkatkan dengan mengoptimalkan sumber daya yang ada, serta dukungan dari jajaran pimpinan fakultas dan universitas.

Kata kunci: kurikulum, pendidikan kedokteran, lingkungan pembelajaran, DREEM

\section{PENDAHULUAN}

World Federation for Medical Education (WFME) merekomendasikan standar global untuk pendidikan dasar kedokteran. Standar ini terdiri atas 9 area dengan total 36 sub area. Area ini berisi struktur, proses dan outcome dari pendidikan kedokteran. Area ini terdiri atas ${ }^{1}$ : mission and objectives; educational programme; assessment of students; students; academic staff/faculty; educational resources; programme evaluation; governance and administration; dan continous renewal.

Area assessment of students meliputi 2 sub area yang dapat dinilai yaitu assessment methods dan relation between assessment and learning. Assessment methods dapat diartikan sebagai evaluasi terhadap metode penilaian mahasiswa kedokteran yaitu ujian formatif, sumatif, tes presentasi, tes tulis, dan Objective Structured Clinical Examination (OSCE). Untuk sub area relation between assessment and learning dapat diartikan bahwa prinsip penilaian, metode dan penerapannya harus sejalan dengan tujuan pendidikan dan mendukung kegiatan pembelajaran. Salah satu aspek evaluasi yang bisa dilakukan adalah dengan menilai suasana akademik yang dirasakan oleh mahasiswa kedokteran dan pencapaian nilai akademik mahasiswa selama menempuh pendidikan di institusi pendidikan kedokteran.

Penilaian suasana akademik merupakan implementasi dari pelaksanaan sebuah kurikulum. ${ }^{2}$ Rothman dan Ayoade ${ }^{3}$ menyatakan bahwa lingkungan pembelajaran atau suasana akademik merupakan manifestasi dari efek yang dialami mahasiswa dalam pelasanaan sebuah kurikulum. ${ }^{3}$ Komponen yang terdapat dalam suasana akademik/lingkungan pembelajaran yang sesuai dengan kurikulum tesebut, dan merupakan karakteristik dari sebuah institusi pendidikan kedokteran. ${ }^{2}$

Prodi Pendidikan Dokter Fakultas Kedokteran Universitas Tanjungpura (FK UNTAN) menerapkan Kurikulum Berbasis Kompetensi (KBK) sesuai dengan Kurikulum Inti Pendidikan Tinggi III (KIPDI III). Kurikulum ini diterapkan sejak tahun ajaran 2005/2006, dan telah dievaluasi menjadi Kurikulum 2013, sejak tahun ajaran 2013/2014.

Lingkungan pembelajaran merupakan manifestasi dari sebuah kurikulum, sehingga penilaian lingkungan tersebut dalam sebuah institusi pendidikan kedokteran, merupakan bagian dari pelaksanaan evaluasi kurikulum. Pengukuran yang dilakukan oleh Rothman dan Ayoede, ${ }^{3}$ terhadap perubahan yang terjadi dalam sebuah lingkungan pembelajaran, yang disebabkan oleh perubahan kurikulum, dinilai sebagai bagian yang tidak terpisahkan dari pelaksanaan evaluasi kurikulum. WFME menyatakan bahwa lingkungan pembelajaran merupakan salah satu target dalam pelaksanaan evaluasi di program pendidikan kedokteran. ${ }^{3}$

Kuesioner Dundee Ready Education Environment Measure (DREEM) merupakan salah satu alat yang tepat untuk dalam melakukan pengukuran lingkungan pembelajaran. Kuisioner ini mengukur persepsi mahasiswa terhadap proses pembelajaran, persepsi terhadap dosen, persepsi terhadap 
pencapaian akademik, persepsi terhadap suasana pembelajaran (academic atmosphere) dan persepsi terhadap lingkungan sosial. ${ }^{4}$ Penelitian ini bertujuan untuk menilai persepsi mahasiswa PSPD FK UNTAN terhadap lingkungan pembelajaran pada tahun akademik 2013/2014.

\section{METODE}

Penelitian ini merupakan penelitian deskriptif potong-lintang yang bertujuan untuk mengukur lingkungan pembelajaran pada mahasiswa PDPD FK UNTAN. Pengukuran dilakukan melalui kuesioner DREEM (dalam bahasa Inggris). Penelitian ini dilakukan pada bulan November 2013 di FK UNTAN, Pontianak, Kalimantan Barat.

Populasi target penelitian ini adalah mahasiswa PSPD FK UNTAN angkatan 2007 hingga angkatan 2012, yang aktif pada tahun ajaran 2013/2014. Pengambilan sampel diambil secara consecutive sampling.

Kuesioner DREEM terdiri dari 50 pertanyaan yang berisi tentang persepsi mahasiswa terhadap proses pembelajaran-12 nomor (nilai maksimal adalah 48), persepsi terhadap dosen-11 nomor (nilai maksimal 44), persepsi terhadap pencapaian akademik-7 nomor (nilai maksimal 28), persepsi terhadap suasana pembelajaran (academic atmosphere)-12 nomor (nilai maksimal 48) dan persepsi terhadap lingkungan sosial-8 nomor (nilai maksimal 32). Penilaian dilakukan dengan menggunakan skala Likert, mulai dari setuju hingga sangat tidak setuju. Nilai 0 diberikan untuk sangat tidak setuju, dan nilai 4 untuk setuju. Nilai maksimal untuk kuesioner ini adalah 200, yang menunjukkan sebuah lingkungan pembelajaran yang ideal menurut persepsi mahasiswa. ${ }^{5}$ Hasil nilai total DREEM diinterpretasikan sebagai berikut ${ }^{6}: 0-50$ (very poor), 51-100 (plenty of problems), 101-150 (more positive than negative), dan 151-200 (excellent).

\section{HASIL DAN PEMBAHASAN}

Jumlah responden yang terlibat dalam penelitian ini sebanyak 142 mahasiswa, dengan distribusi tahun 1 (angkatan 2012) 54,1\% dari seluruh total 74 mahasiswa angkatan 2012 yang aktif di tahun ajaran 2013/2014, tahun 2 (angkatan 2011) sebanyak 66,7\% (dari total 75 mahasiswa), tahun 3 (angkatan 2010) sebanyak 52,3\% (dari total 65 mahasiswa), tahun 4 (angkatan 2009) sebanyak 10,9\% (dari total 92 mahasiswa), tahun 5 (angkatan 2008) sebanyak 8,6\% (dari total 81 mahasiswa), dan tahun 6 (angkatan 2007) sebanyak 2,9\% (dari total 35 mahasiswa).

Pengukuran dengan menggunakan kuesioner DREEM yang diisi oleh 142 responden, menyatakan bahwa total nilai dari tahun pertama hingga tahun keenam adalah 142,55, yang dapat diinterpretasikan sebagai persepsi yang positif dari mahasiswa terhadap lingkungan pembelajaran yang ada saat ini. Nilai total tersebut, menunjukkan bahwa mahasiswa menjawab pada kisaran nilai 2 hingga 3 (rata-rata 2,851), yang berarti bahwa persepsi mahasiswa terhadap lingkungan pembelajaran dan pelaksanaan KBK yang ada saat ini di PSPD FK UNTAN telah cukup memadai, dan dapat ditingkatkan dengan memanfaatkan sarana dan prasarana yang ada. Distribusi nilai total untuk masing-masing parameter yang dinilai dapat dilihat pada Tabel 1.

Total nilai DREEM mahasiswa yang berada pada tahun 1-6 tidak memiliki perbedaan yang bermakna (selisih total nilai DREEM kurang dari 10\%). Perbedaan nilai total DREEM berikut interpretasi skala Likert yang digunakan pada kuesioner DREEM dapat dilihat pada gambar 1, dimana tidak ada responden yang mengisi kuesioner dengan nilai 0 (nol).

Nilai total DREEM yang diperoleh pada penelitian ini adalah 142,55/200 yang menunjukkan bahwa mahasiswa menganggap lingkungan pembelajaran yang ada saat ini, termasuk dosen, lingkungan sosial, proses pembelajaran, capaian akademik, dan suasana pembelajaran, berada dalam lingkungan yang positif. Mahasiswa menganggap bahwa lingkungan tersebut masih dapat ditingkatkan, dengan mengoptimalkan sumber daya yang ada. Hal ini sesuai dengan penelitian sebelumnya yang telah dilaksanakan di Fakultas Kedokteran Universitas Indonesia pada tahun 2008, yaitu 120,10/200, ${ }^{4}$ Faculty of Medicine, Mesir tahun 2013 yaitu 113,5/200, ${ }^{5}$ dan di Medical College of Central India, tahun 2014 yaitu 120,10/200.7

Genn ${ }^{2}$ menyatakan bahwa perubahan kurikulum diharapkan dapat menciptakan lingkungan pem- 
Tabel 1. Interpretasi Parameter DREEM dari Seluruh Responden

\begin{tabular}{lcl}
\multicolumn{1}{c}{$\begin{array}{c}\text { Parameter } \\
\text { Nilai Maksimal) }\end{array}$} & $\begin{array}{c}\text { Rerata Nilai } \\
\text { (Skor) }\end{array}$ & \multicolumn{1}{c}{ Interpretasi } \\
\hline $\begin{array}{l}\text { Persepsi mahasiswa terhadap proses } \\
\text { pembelajaran }\end{array}$ & $\begin{array}{l}35,58 \\
(48)\end{array}$ & $\begin{array}{l}\text { Proses berlangsung baik dan dapat } \\
\text { ditingkatkan }\end{array}$ \\
\hline $\begin{array}{l}\text { Persepsi mahasiswa terhadap dosen } \\
\text { (44) }\end{array}$ & 32,07 & $\begin{array}{l}\text { Dosen telah menjalankan tugasnya } \\
\text { dengan baik }\end{array}$ \\
\hline $\begin{array}{l}\text { Persepsi mahasiswa terhadap suasana } \\
\text { pembelajaran }\end{array}$ & $(2,92)$ & $\begin{array}{l}\text { Suasana pembelajaran cukup kondusif } \\
\text { untuk mendukung pembelajaran dan }\end{array}$ \\
(48) & $(2,54)$ & dapat ditingkatkan \\
\hline $\begin{array}{l}\text { Persepsi mahasiswa terhadap capaian } \\
\text { akademik mahasiswa }\end{array}$ & 21,3 & Prestasi akademik mahasiswa baik \\
$\begin{array}{l}(32) \\
\text { Persepsi mahasiswa terhadap lingkungan }\end{array}$ & $(2,66)$ & \\
sosial & 23,1 & Lingkungan kampus sangat \\
$(28)$ & $(3,3)$ & mendukung proses pembelajaran \\
\hline $\begin{array}{l}\text { Total nilai DREEM } \\
(200)\end{array}$ & 142,55 & Mahasiswa mempunyai persepsi yang \\
\hline
\end{tabular}

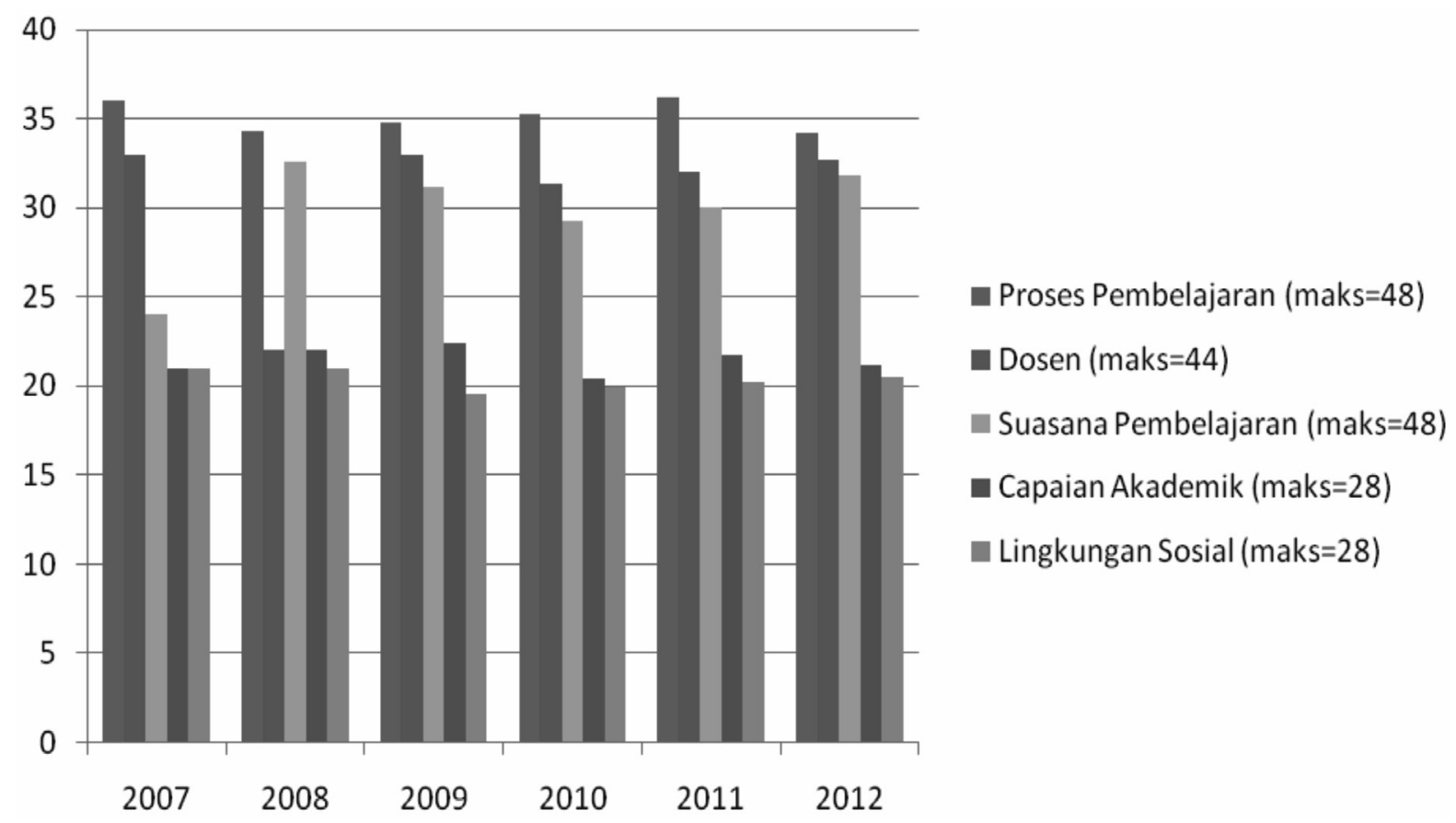

Gambar 1. Distribusi Nilai Total DREEM Responden 
belajaran yang baik untuk mahasiswa. Perbaikan yang berkelanjutan dalam lingkungan pembelajaran hanya dimungkinkan untuk memperbaiki kelemahan yang ada, dengan memanfaatkan sumber daya yang ada . ${ }^{2}$

Beberapa faktor yang dapat mempengaruhi nilai ini adalah metode pembelajaran yang diterapkan oleh institusi pendidikan kedokteran, sesuai hasil penelitian yang didapat, tampak bahwa metode PBL (Problem based learning) menunjukkan nilai yang lebih tinggi daripada metode pembelajaran konvensional. Hal ini didasarkan bahwa pada penerapan metode student-centered, mahasiswa diharapkan lebih bermotivasi dan bertanggung jawab terhadap lingkungan pembelajarannya sendiri. ${ }^{6}$ PSPD FK UNTAN telah menerapkan metode pembelajaran PBL sejak didirikan pada tahun ajaran 2005/2006. Hal ini juga dapat menjadi salah satu alasan bagi mahasiswa yang memberikan penilaian positif terhadap lingkungan pembelajaran, karena mahasiswa telah terbiasa dengan metode PBL sejak menjalani pendidikan kedokteran.

Faktor kedua yang dapat mempengaruhi nilai ini adalah adanya persepsi mahasiswa bahwa dosen yang terlibat dalam pendidikan kedokteran, mempunyai kompetensi yang sesuai dan dapat mengarahkan mahasiswa dalam pelaksanaan PBL. (ditunjukkan dengan nilai rata-rata adalah 2,92/ near with moving to the right direction). Hal ini dapat disebabkan bahwa sebagian besar, dosen telah menjalani pelatihan sebagai fasilitator dalam pembelajaran PBL. Hal ini juga sesuai dengan penelitian sebelumnya, yang menyatakan bahwa dosen yang berpengalaman dapat mempengaruhi pernilaian mahasiswa dalam pelaksanaan sebuah kurikulum. ${ }^{8}$

Faktor lain yang dapat mempengaruhi adalah perbedaan jalur masuk mahasiswa di institusi pendidikan kedokteran. Prodi Pendidikan Kedokteran FK UNTAN, ada beberapa jalur masuk yang diterapkan, yaitu ikatan dinas (kerja sama dengan Pemerintah Daerah/Kota di Kalimantan Barat), jalur mandiri, dan melalui jalur SBMPTN. Jalur masuk melalui kerja sama dengan Pemerintah daerah/ Kota di Kalimantan Barat, merupakan salah satu sumber pembiayaan yang cukup besar bagi institusi, sehingga dapat digunakan untuk melengkapi sarana dan prasarana yang dibutuhkan dalam pembelajaran pendidikan kedokteran. Sebagai contoh, saat ini PSPD FK UNTAN telah memiliki laboratorium uji kompetensi berbasis computer (computer based test) dan berbasis ketrampilan (OSCE),sebagai salah satu kelengkapan dalam Uji Kompetensi Mahasiswa Program Profesi Dokter (UKMPPD).

Hasil penelitian yang diperoleh menunjukkan bahwa rata-rata jawaban mahasiswa berada pada kisaran 2-3 (untuk masing-masing parameter). Hal ini berarti bahwa persepsi mahasiswa terhadap lingkungan pembelajaran lebih bernilai positif.

\section{KESIMPULAN}

Lingkungan pembelajaran di PSPD FK UNTAN, yang telah menerapkan metode pembelajaran PBL sejak didirikan pada tahun 2005, dinilai positif oleh mahasiswa, dengan nilai total DREEM yang diperoleh pada penelitian ini adalah 142,55/200. Interpretasi dari hasil tersebut dapat disimpulkan bahwa mahasiswa berpendapat bahwa lingkungan pembelajaran tersebut dapat ditingkatkan dengan mengoptimalkan sumber daya yang ada, serta dukungan dari jajaran pimpinan fakultas dan universitas.

\section{DAFTAR PUSTAKA}

1. World Federation of Medical Education. International standards in medical education: assessment and acreditaion of medical schooleducational programme: a WFME positions paper. Med educ. 1998;32:549-58.

2. Genn JM, AMEE. Medical Education Guide no.23 (part 1): curriculum, environment, climate, quality, and change in medical education. Unifying perceptive. Med Teach. 2001;23:337-44.

3. Rothman AI, Ayoade F. the development of a learning environment: a questionnaire for use in curriculum evaluation. J of Med Educ. 1970;45:754-9.

4. Soemantri D, RoffS. McAlaer S. Student perception's of the educational environment in the midst of curriculum change. Med J Indones. 2008;17(1):57-62.

5. Youssef WT, El-Wazir YM, Ghaly MS, El-Khadragy RA. Evaluation of the learning environment at the faculty of medicine, Suez Canal University: students perceptions. Intel Prop Rights. 2013;1(1): 1-7. 
6. McAlaer S, Roff S. A practical guide to using Dundee ready education environment measure (DREEM). In curricular, environment, climate and change in medical education: a unifying perspective. AMEE education guide no.23 Dundee; Association for medical education in Europe edited by Genn JM 2001; 29-33.

7. Dashputra A, Chari S, Gade S. Perception of educational environment in a private medical college in central india. Int J Edu Sci. 2014; 6(3): 489-96.
8. Yusoff MSB, Jaafar R. Arzuman H, Arifin WN, Pa MNM. Perceptions of medical students regarding educational climate at different phases of medical training in a Malaysian medical school. Education in Medicine Journal. 2013; 5(3). Diakses melalui http://www.eduimed.com/index.php/eimj/rt pada tanggal 24 Maret 2015. 